\title{
INFLUÊNCIA DE ESPÉCIES ARBÓREAS NO MICROCLIMA E CONFORTO TÉRMICO DE SEU ENTORNO IMEDIATO SOB CONDIÇÕES CLIMÁTICAS DO CERRADO GOIANO
}

\author{
INFLUENCE OF TREE SPECIES ON MICROCLIMATE AND THERMAL COMFORT IN \\ THEIR IMMEDIATE SURROUNDINGS UNDER BRAZILIAN CERRADO CONDITIONS
}

Regis de Castro Ferreira1 ${ }^{1}$, Carla Rosana Azambuja Herrman²

\begin{abstract}
RESUMO
Avaliou-se a influência do sombreamento pelas espécies arbóreas Lophantera lactescens Ducke (lanterneiro ou chuva de ouro), Caesalpinia pluviosa var. peltophoroides (Benth.) G. P. Lewis (sibipiruna), Sapindus saponaria L. (saboneteira) e Stryphnodendron adstringens Mart (Coville) (barbatimão) sobre a Temperatura de Bulbo Seco (TBS), Carga Térmica Radiante (CTR), Umidade Relativa do Ar (UR) e do conforto térmico sob condições climáticas de Goiânia-GO. Quantificou-se a atenuação das variáveis pelo cálculo percentual da variação relativa dos dados à sombra, a $5 \mathrm{~m}$ e a $10 \mathrm{~m}$ em relação aos valores a 15 $\mathrm{m}$ (pleno sol). Os resultados mostraram os efeitos positivos na atenuação da TBS, da CTR e nos incrementos da UR e do conforto térmico. Os melhores resultados para a atenuação da TBS foram obtidos pela sibipiruna e o barbatimão com médias de atenuações entre $5 \%$ e $10 \%$ A saboneteira e a sibipiruna obtiveram incrementos superiores a $30 \%$ na UR e a sibipiruna promoveu atenuações da CTR à sombra na ordem de $15 \%$. A comparação dos resultados obtidos em campo com o critério de conforto adotado demonstrou a influência positiva das espécies arbóreas estudadas na melhoria do microclima do seu entorno imediato.
\end{abstract}

Palavras-chave: Arborização Urbana; Sombreamento; Planejamento Urbano; Ambiência.

\begin{abstract}
This study evaluated the influence of shading provided by tree species Lophantera lactescens Ducke, Caesalpinia pluviosa var. peltophoroides (Benth.) G. P. Lewis, Sapindus saponaria L. and Stryphnodendron adstringens Mart (Coville) on Dry Bulb Temperature (DBT), Radiant Heat Load (RHL), Relative Humidity $(\mathrm{RH})$ and thermal comfort on climatic conditions of Goiania, GO, Brazil. For this purpose, it was quantified the mitigation of the environmental variables by the percentage calculation of the relative change of the data under shades, $5 \mathrm{~m}$ and $10 \mathrm{~m}$ from the values to $15 \mathrm{~m}$ (full sun). The results showed positive effects on the DBT and RHL attenuation, and increasing of the RU and thermal comfort. The best results in terms of DBT mitigation were obtained by Caesalpinia pluviosa and Stryphnodendron adstringens with DBT average mitigations between $5 \%$ and $10 \%$ The Sapindus saponaria and Caesalpinia pluviosa promoted increments over $30 \%$ in $\mathrm{RH}$ and Caesalpinia pluviosa promoted RHL mitigations of approximately $15 \%$. The comparison of results showed that the tree species improve the microclimate of their immediate surroundings.
\end{abstract}

Keywords: Urban Afforestation; Shading; Urban Planning; Thermal Comfort.

Recebido em 02.05.2016 e aceito em 06.06.2016

1 Engenheiro Agrônomo, Dr. Professor da Escola de Agronomia da Universidade Federal de Goiás, Goiânia-GO. E-mail: rcastro@ufg.br.

2 Arquiteta, MSc. Professora do Instituto Federal de Educação, Ciências e Tecnologia de Goiás, Goiânia-GO. Email: crah@cefetgo.br. 


\section{INTRODUÇÃO}

A radiação solar influencia outros elementos meteorológicos responsáveis pelo conforto térmico (temperatura, umidade relativa e vento). Por sua vez, a arborização urbana é considerada o método mais natural para a mitigação das consequências nocivas da intensa radiação solar à saúde humana.

As copas das árvores são capazes de modificar o microclima de seu entorno por meio da reflexão, transmissão e absorção da radiação solar e controle da velocidade do vento. Em climas tropicais, a possibilidade de alterar as condições de vento e sombra pode modificar o microclima e melhorar o conforto térmico humano (LIN et al., 2010).

O planejamento da arborização urbana leva em conta diferentes critérios, como forma e disposição das raízes, altura da árvore adulta, estética e outros. Contudo, praticamente não se tem considerado o conforto térmico urbano como parte dessa análise.

Além do efeito de redução na temperatura ambiente, o uso de vegetação pode proporcionar uma significativa redução no consumo energético para resfriamento dos ambientes construídos (PANDIT; LABAND, 2010). Donovan e Butry (2009), estudando a influência da arborização no consumo elétrico para resfriamento em uma amostra de 460 residências no verão de Sacramento, Califórnia (EUA), reportaram redução de 185 kWh (5,2\%) no consumo. Laband (2009) apresentou resultados da ordem de 2,6 vezes mais consumo de energia para refrigerar residências a pleno sol quando comparadas àquelas em plena sombra em Beauregard, Alabama (EUA).

As pesquisas brasileiras sobre o impacto da vegetação no conforto ambiental dos espaços urbanos e ambientes construídos iniciaram-se na década de 1990 com os trabalhos pioneiros de Sattler (1991) e Bueno (1998). Desde então, um razoável volume de informações vêm sendo produzido pelos pesquisadores brasileiros sobre o assunto, em diversas abordagens, tais como: a quantificação da melhoria do conforto térmico no ambiente construído com uso de vegetação no entorno das edificações (BARTOLOMEI, 2003), a influência de fragmentos florestais urbanos no microclima das cidades (DACANAL et al., 2010), a avaliação do raio de influência e da arquitetura das copas das árvores (ABREU-HARBICH; LABAKI, 2010; ABREU-HARBICH; LABAKI; MATZARAKIS, 2015), a avaliação quali-quantitativa do efeito da arborização no microclima e percepção da população (MARTINI et al., 2014; MEIRA et al., 2015), análise e atenuação de ilhas de calor (NÓBREGA; VITAL, 2010; NASCIMENTO; OLIVEIRA, 2010; SANTOS JÚNIOR; LACERDA; GOMES, 2013), o uso de ferramentas computacionais e simulações (SPANGENGERG et al., 2008; MINELA; HONJO; KRÜGER, 2012), dentre outras. 
Contudo, ressalta-se que os trabalhos têm sido conduzidos sob condições bioclimáticas das regiões sul, sudeste, norte e nordeste, com a ausência de estudos contemplando a região do Planalto Central inserida no bioma Cerrado, cujo clima é o Tropical sazonal, de inverno seco, notadamente conhecido por seus extremos sazonais em termos de intensidade de radiação solar, temperatura e precipitação.

Neste contexto, o presente trabalho teve como objetivo estudar a contribuição do sombreamento por espécies arbóreas nativas do Brasil, incluindo espécies nativas do Cerrado, sobre o microclima de seu entorno imediato mediante a modificação das variáveis ambientais relacionadas ao conforto térmico - temperatura, umidade relativa do ar e carga térmica radiante - e avaliação de índice de conforto térmico humano, nas condições climáticas do Município de Goiânia, Estado de Goiás.

\section{MATERIAL E MÉTODOS}

\section{Clima de Goiânia-GO}

Goiânia localiza-se entre $16^{\circ} 40^{\prime}$ S e $49^{\circ} 15^{\prime} \mathrm{O}$, à altitude média de 749 metros. Pela classificação climática de Köppen-Geiger, seu clima é classificado como Aw (quente e semiúmido com estação seca bem definida, de maio a setembro) (KOTTEK et al., 2006). A temperatura média anual é de $23,2^{\circ} \mathrm{C}$, e médias das máximas e mínimas de $29,8^{\circ} \mathrm{C}$ e $17,9^{\circ} \mathrm{C}$, respectivamente. A precipitação média anual é de 1575,9 mm e a insolação anual média é de 2588,1 horas. A Tabela 1 apresenta os valores médios dos elementos meteorológicos das Normais Climatológicas para o município de Goiânia-GO.

Tabela 1. Normais Climatológicas (1961-1990) para o município de Goiânia, Goiás Table 1. Climatological normals (1961-1990) for the municipality of Goiânia, GO

\begin{tabular}{|c|c|c|c|c|c|c|c|c|c|}
\hline & $\begin{array}{c}\text { Temp. } \\
\text { Máx }\left({ }^{\circ} \mathrm{C}\right)\end{array}$ & $\begin{array}{l}\text { Temp. } \\
\text { Méd( }{ }^{\circ} \\
\text { C) }\end{array}$ & $\begin{array}{l}\text { Temp. } \\
\text { Mín }\left({ }^{\circ} \mathrm{C}\right)\end{array}$ & $\begin{array}{c}\text { Amplitude } \\
\left({ }^{\circ} \mathrm{C}\right)\end{array}$ & $\begin{array}{l}\text { UR( } \\
\%)\end{array}$ & $\begin{array}{l}\text { Precip. } \\
\text { (mm) }\end{array}$ & $\begin{array}{l}\text { Nebul. } \\
\text { (h) }\end{array}$ & $\begin{array}{l}\text { Insol. } \\
\text { Diária }\end{array}$ & $\begin{array}{l}\text { Vel. dos } \\
\text { Ventos } \\
\left(\mathrm{m} \mathrm{s}^{-1}\right)\end{array}$ \\
\hline Jan & 29,2 & 24,5 & 19,7 & 9,5 & 75 & 270,3 & 7,1 & 5,7 & 3,0 \\
\hline Fev & 29,4 & 24,6 & 19,7 & 9,7 & 76 & 213,3 & 7,1 & 5,4 & 3,0 \\
\hline Mar & 30,1 & 24,8 & 19,5 & 10,6 & 74 & 209,6 & 6,6 & 6,6 & 3,0 \\
\hline Abr & 30,0 & 24,3 & 18,5 & 11,5 & 71 & 120,6 & 5,3 & 7,7 & 3,0 \\
\hline Mai & 29,1 & 22,6 & 16,0 & 13,1 & 65 & 36,4 & 4,4 & 8,2 & 3,0 \\
\hline Jun & 28,7 & 21,2 & 13,7 & 15,0 & 60 & 9,5 & 3,4 & 9,0 & 3,5 \\
\hline Jul & 28,9 & 21,1 & 13,2 & 15,7 & 53 & 6,2 & 3,1 & 9,1 & 3,0 \\
\hline Ago & 31,2 & 23,1 & 15,0 & 16,2 & 47 & 12,7 & 3,0 & 8,7 & 3,0 \\
\hline Set & 31,9 & 25,0 & 18,1 & 13,8 & 53 & 47,6 & 4,1 & 7,2 & 3,5 \\
\hline Out & 31,0 & 25,3 & 19,5 & 11,5 & 65 & 170,9 & 6,3 & 5,9 & 3,0 \\
\hline Nov & 29,7 & 24,6 & 19,6 & 10,1 & 73 & 220,0 & 7,0 & 5,8 & 2,5 \\
\hline Dez & 28,9 & 24,3 & 19,7 & 9,2 & 76 & 258,8 & 7,6 & 5,5 & 2,5 \\
\hline Ano & 29,8 & 24,8 & 17,9 & 11,9 & 66 & $1.575,9$ & 5,4 & 7,1 & - \\
\hline
\end{tabular}




\section{Seleção dos locais de medição e dos indivíduos arbóreos}

Selecionou-se os locais de medição a partir das características específicas do entorno:

i. Situar-se em ilha central de avenida ou em espaço aberto de área urbanizada;

ii. Existir pavimentação artificial e edifícios em seu entorno e elementos que caracterizem condições de urbanização;

iii. Inexistir sombreamento do indivíduo estudado por qualquer tipo de elemento físico construído ou por outro indivíduo arbóreo.

As espécies foram selecionadas considerando sua ocorrência em regiões tropicais e no cerrado e a partir de sua utilização para arborização urbana, conforme o Plano Diretor de Arborização Urbana de Goiânia (AMMA, 2007). Assim sendo, selecionou-se as seguintes espécies: Lophantera lactescens Ducke (lanterneiro ou chuva de ouro), Caesalpinia pluviosa var. peltophoroides (Benth.) G. P. Lewis (sibipiruna), Sapindus saponaria L.(saboneteira) e Stryphnodendron adstringens Mart (Coville) (barbatimão) (Figura 1). As principais características desses indivíduos arbóreos são apresentadas no Quadro 1.
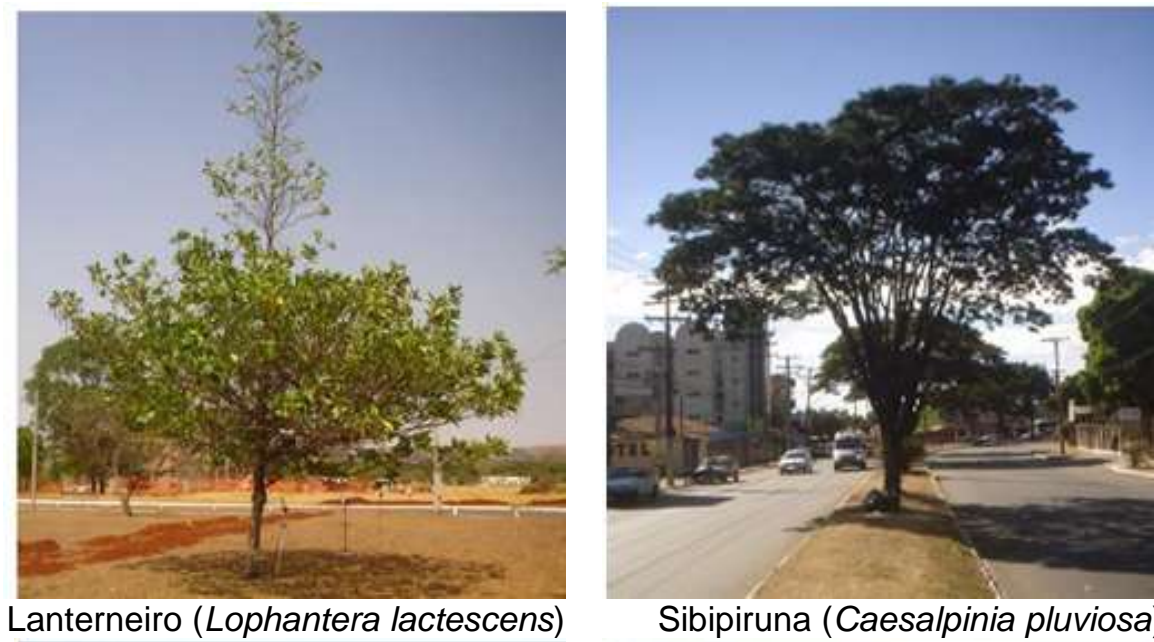

Sibipiruna (Caesalpinia pluviosa)
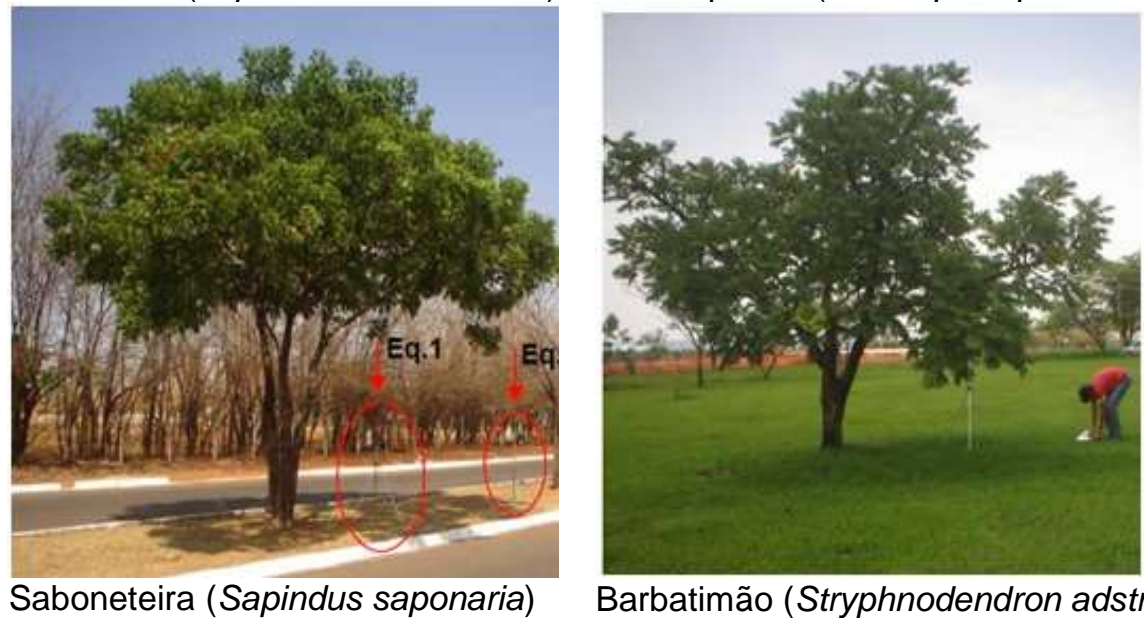

Barbatimão (Stryphnodendron adstringens)

Figura 1. Indivíduos arbóreos e seu entorno imediato

Figure 1. Individual trees and their immediate surroundings 
De acordo com as condições previstas e com as espécies previamente selecionadas chegou-se à localização de um indivíduo por espécie árborea em duas condições distintas: i) em canteiro central de avenida, nos casos da Sibipiruna e da Saboneteira; ii) em espaço aberto de áreas urbanizadas, nos casos da Lanterneira e do Barbatimão (Figura 2). A localização dos indivíduos estudados no Município de Goiânia - GO está representada na Figura 3.

\begin{tabular}{|c|c|}
\hline $\begin{array}{l}\text { Lophantera lactescens Ducke - } \\
\text { lanterneiro ou chuva de ouro }\end{array}$ & $\begin{array}{l}\text { - } \quad \text { Altura do fuste: } 5 \mathrm{~m} \\
\text { - } \quad \text { Diâmetro do tronco: } 32 \mathrm{~cm} \\
\text { - } \quad \text { Casca do tronco: pardacenta fina } \\
\text { - } \quad \text { Diâmetro da copa: } 5 \mathrm{~m} \\
\text { - } \quad \text { Tipo da copa: cônica ou piramidal } \\
\text { - } \quad \text { Comprimento da folha: } 16 \text { a } 22 \mathrm{~cm} \\
\text { - Largura da folha: } 8 \text { a } 11 \mathrm{~cm} \\
\text { - } \quad \text { Cor da folha: verde escura } \\
\text { - Informações ecológicas: semidecídua }\end{array}$ \\
\hline $\begin{array}{l}\text { Caesalpinia pluviosa var. } \\
\text { peltophoroides (Benth.) G. P. Lewis - } \\
\text { sibipiruna }\end{array}$ & $\begin{array}{l}\text { - } \quad \text { Altura do fuste: } 7 \mathrm{~m} \\
\text { - } \quad \text { Diâmetro do tronco: } 35 \mathrm{~cm} \\
\text { - } \quad \text { Casca do tronco: escamosa } \\
\text { - } \quad \text { Densetro da copa: } 6 \mathrm{~m} \\
\text { - } \quad \text { Tipo da copa: arredondada } \\
\text { - } \quad \text { Comprimento da folha: } 20 \text { a } 25 \mathrm{~cm} \\
\text { - } \quad \text { Corgura da folha: } 2 \text { a } 3 \mathrm{~cm} \\
\text { - Informações ecológicas: perenifólia }\end{array}$ \\
\hline Sapindus saponaria L. saboneteira & $\begin{array}{l}\text { - } \quad \text { Altura do fuste: } 4 \mathrm{~m} \\
\text { - } \quad \text { Caâmetro do tronco: } 28 \mathrm{~cm} \\
\text { - } \quad \text { Diâmetro da copa: } 6 \mathrm{~m} \\
\text { - } \quad \text { Densidade da copa: densa } \\
\text { - } \quad \text { Compo da copa: globosa } \\
\text { - } \quad \text { Largura da folha: } 3 \text { a } 4 \mathrm{~cm} \\
\text { - } \quad \text { Infor da folha: verde } \\
\text { - } 12 \mathrm{~cm} \\
\end{array}$ \\
\hline $\begin{array}{l}\text { Stryphnodendron adstringens Mart } \\
\text { (Coville) - barbatimão }\end{array}$ & $\begin{array}{l}\text { - } \quad \text { Altura do fuste: } 3 \mathrm{~m} \\
\text { - } \quad \text { Diâmetro do tronco: } 26 \mathrm{~cm} \\
\text { - } \quad \text { Casca do tronco: rugosa e espessa } \\
\text { - } \quad \text { Denensidade da copa: } 4 \mathrm{~m} \\
\text { - } \quad \text { Tipo da copa: alongada } \\
\text { - } \quad \text { Comprimento da folha: } 3 \text { a } 6 \mathrm{~cm} \\
\text { - } \quad \text { Largura da folha: } 0,7 \text { a } 1,5 \mathrm{~cm} \\
\text { - } \quad \text { Infor da folha: verde claro } \\
\text { açóes ecológicas: decídua }\end{array}$ \\
\hline
\end{tabular}

Quadro 1. Características das espécies arbóreas avaliadas

Board 1. Characteristics of the tree species evaluated 

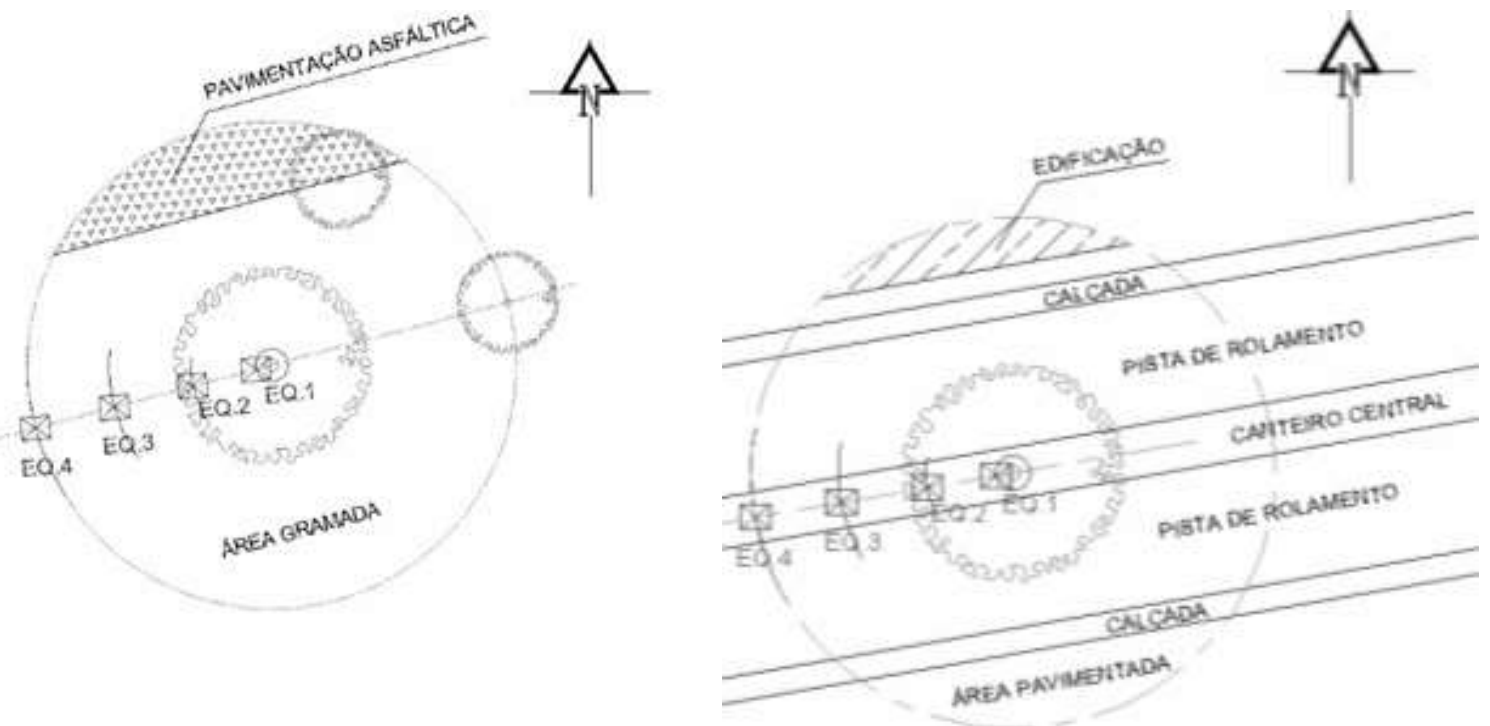

A
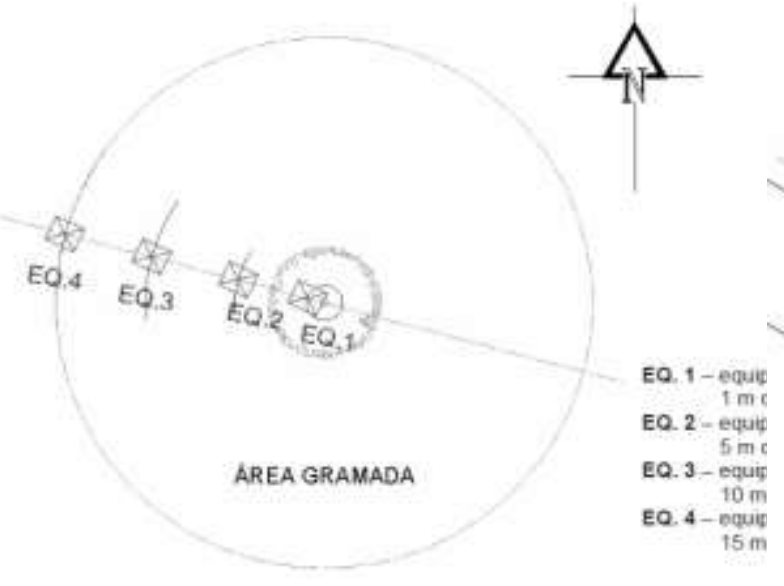

C

B

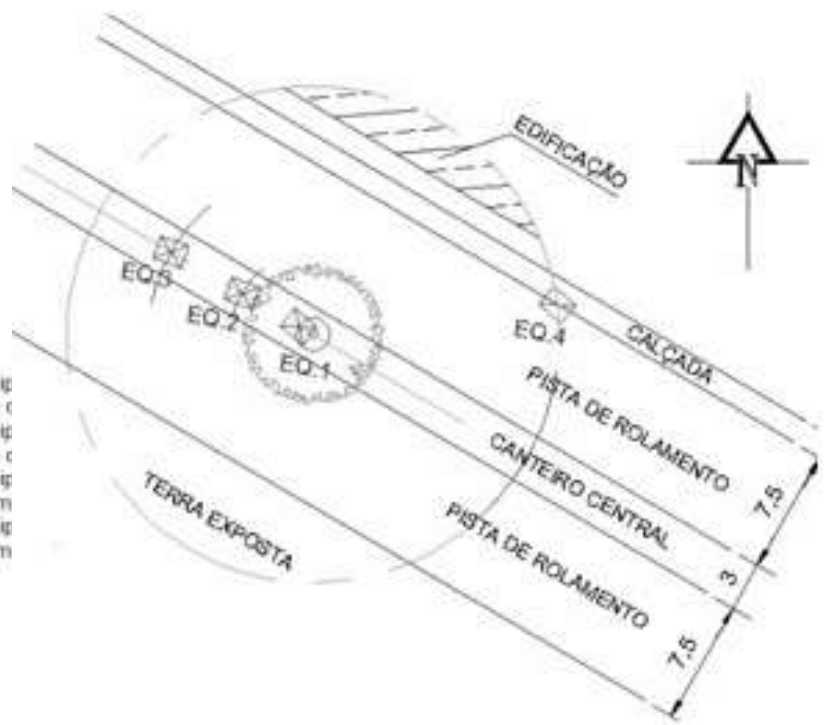

$\mathrm{D}$

Eq. 1 - Equipamento a $1 \mathrm{~m}$ do tronco (sombra); Eq. 2 - Equipamento a $5 \mathrm{~m}$ do tronco; Eq. 3 Equipamento a $10 \mathrm{~m}$ do tronco; Eq. 4 - Equipamento a $15 \mathrm{~m}$ do tronco (pleno sol)

Figura 2. Representação esquemática do entorno dos indivíduos arbóreos avaliados. A) Lanterneiro; B) Sibipiruna; C) Barbatimão; D) Saboneteira

Figure 2. Schematic representation of the tree species surrounding. A) Lophantera lactescens; B) Caesalpinia pluviosa; C) Stryphnodendron adstringens; and D) Sapindus saponaria 


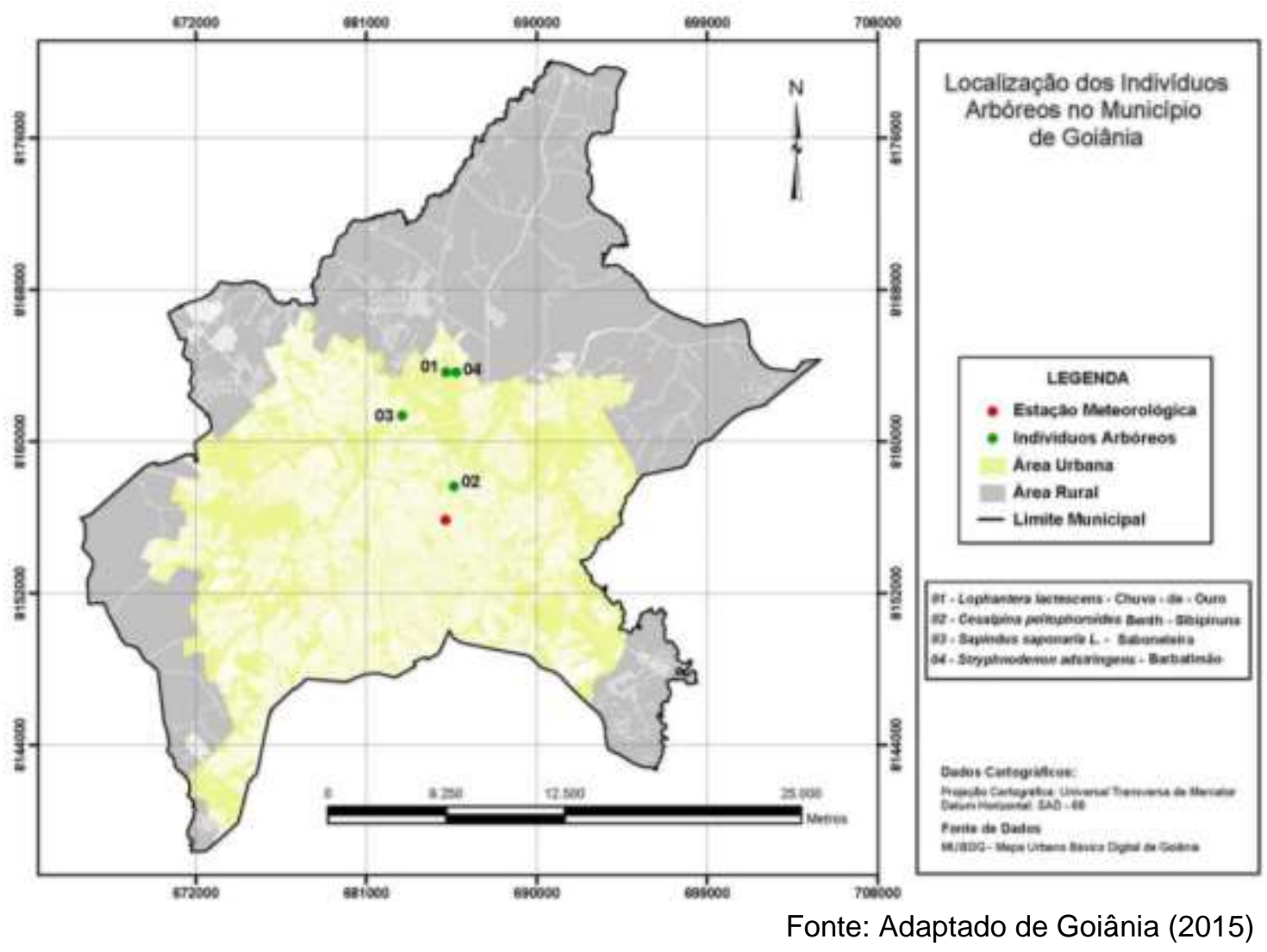

Figura 3. Localização dos indivíduos arbóreos avaliados no município de Goiânia-GO

Figure 3. Localization of the evaluated trees in Goiânia-GO

\section{Obtenção dos parâmetros ambientais}

Foram utilizados quatro conjuntos de equipamentos de medição, nomeados e posicionados conforme a Figura 2, compostos cada um por um termômetro de globo negro e um psicrômetro de ventilação natural para a obtenção dos valores de temperatura de globo negro e de umidade relativa do ar, respectivamente. Para as medições de temperatura de bulbo seco foram utilizados os termômetros de bulbo seco (escalas de $-10^{\circ} \mathrm{C}$ a $110^{\circ} \mathrm{C}$ ) dos psicrômetros de ventilação natural. A velocidade do vento foi determinada por um anemômetro digital portátil.

Os equipamentos foram dispostos de forma a possibilitar a avaliação de raios de influência (Figura 2) dos indivíduos arbóreos sobre as variáveis ambientais por meio da interpretação e análise das Temperaturas de Bulbo Seco (TBS, em $\left.{ }^{\circ} \mathrm{C}\right)$, da Umidade Relativa do $\operatorname{Ar}(\%)$ e da Carga Térmica Radiante $\left(\mathrm{W} \mathrm{m}^{-2}\right)$

As seguintes hipóteses foram levantadas para fins de confirmação do efeito dos indivíduos arbóreos estudados em seu entorno imediato: i) TBS à sombra < TBS a $5 \mathrm{~m}<\mathrm{TBS}$ a $10 \mathrm{~m}<$ TBS ao sol (15 m); ii) UR à sombra > UR $5 \mathrm{~m}>$ UR a $10 \mathrm{~m}>$ UR ao sol (15 m); iii) CTR à sombra $<$ CTR a $5 \mathrm{~m}<$ CTR a $10 \mathrm{~m}<\mathrm{CTR}$ ao sol $(15 \mathrm{~m})$. 
Para serem avaliados os efeitos da radiação solar foi adotado o parâmetro Carga Térmica Radiante (CTR) proposto por Esmay (1979). A CTR quantifica a radiação total recebida pelo objeto de todo o espaço circundante, podendo ser calculada a partir da temperatura de globo negro (equação 1):

$C T R=\sigma(T R M+273)^{4}$

Em que:

CTR = Carga Térmica Radiante $\left(\mathrm{W} \mathrm{m}^{-2}\right)$;

$\sigma=$ constante de Stefan - Boltzmann $5,6710^{-8} \mathrm{~W} \mathrm{~m}^{-2} \mathrm{~K}^{-4}$;

TRM $=$ Temperatura Radiante Média $\left({ }^{\circ} \mathrm{C}\right)$.

Por sua vez, a Temperatura Radiante Média (TRM) corresponde à temperatura ambiente de uma circunvizinhança, considerada uniformemente negra para eliminar o efeito de reflexão, com a qual o corpo (neste caso o globo negro) troca tanta quantidade de energia quanto à do ambiente considerado. A TRM pode foi determinada pelas equações (2) e (3) (ISO, 1998), respectivamente para condições de convecção natural e forçada.

Condições de convecção natural:

$$
T R M=\left[(t g+273)^{4}+0,4 \times 10^{8}|t g-t s|^{0,25}(t g-t s)\right]^{0,25}-273
$$

Condições de convecção forçada:

$$
T R M=\left[(t g+273)^{4}+2,5 \times 10^{8} v^{0,6}(t g-t s)\right]^{0,25}-273
$$

Em que:

$\mathrm{TRM}=$ Temperatura Radiante Média $\left({ }^{\circ} \mathrm{C}\right)$;

$\operatorname{tg}=$ temperatura do termômetro de globo negro $\left({ }^{\circ} \mathrm{C}\right)$;

$v=$ velocidade do $\operatorname{ar}\left(\mathrm{ms}^{-1}\right)$;

ts $=$ temperatura de bulbo seco $\left({ }^{\circ} \mathrm{C}\right)$.

Para determinar-se a equação a aplicar, devem ser calculadas previamente as constantes (equações 4 e 5):

$$
\begin{aligned}
& h_{c g 1}=2,25|t g-t s|^{0.25} \\
& h_{c g 2}=13,46 v^{0.6}
\end{aligned}
$$


Se $h_{c g 1}>h_{c g 2}$, aplica-se a equação para convecção natural, se $h_{c g 1}<h_{c g 2}$, aplica-se a equação para convecção forçada, em que $h_{c g}$ representa o coeficiente de transferência de calor por convecção ao nível do globo $\left(\mathrm{W} \mathrm{m}^{-2}{ }^{\circ} \mathrm{C}^{-1}\right)$.

A coleta dos dados meteorológicos ocorreu no período compreendido entre meados de setembro e início de novembro de 2014, considerado crítico em termos de intensa radiação solar e, consequentemente, elevada temperatura, e baixa umidade relativa do ar. Foi adotado um número de três dias de coleta de dados para cada espécie arbórea. Em cada dia, os dados foram coletados, de hora em hora, no período das 10h às 14h. A delimitação do período horário adotado deu-se pela especificidade do trabalho cujo objetivo foi quantificar a influência do indivíduo no microclima de seu entorno imediato. Desta forma, interessou os períodos do dia em que a sombra de cada indivíduo encontrava-se, efetivamente, sob a sua copa e no entorno de seu tronco. O que não ocorre nos horários que antecedem e precedem o período adotado devido ao movimento aparente do sol.

Para cada espécie arbórea, a coleta dos dados meteorológicos ocorreu em dias diferentes, ou seja, três dias ininterruptos (três repetições) para cada espécie, resultando, portanto, em condições climáticas distintas. Assim, a comparação das atenuações e/ou incrementos das variáveis ambientais (TBS, CTR e UR) entre as espécies se deu pelo cálculo percentual da variação entre os dados, sob o sol e sob a sombra. Para tal, foram determinados o parâmetro "Variação Relativa" às distâncias previamente determinadas (equação 6), ou seja, os raios de influência, para cada variável ambiental ( $\left.\mathrm{VR}_{\mathrm{TBS}}, \mathrm{V} \mathrm{R}_{\mathrm{UR} \%}, \mathrm{VR}_{\mathrm{CTR}}\right)$.

$$
V R=\frac{V A_{\text {sol }}-V A_{\text {sombra/5 /10m }}}{V A_{\text {sol }}} \times 100
$$

Em que:

$V R=$ Variação Relativa (\%);

$V A_{\text {sol }}$ variável obtida com o equipamento ao sol (equipamento posicionado a $15 \mathrm{~m}$ do tronco do indivíduo arbóreo analisado);

$V A_{\text {sombra }}=$ variável obtida com o equipamento à sombra $/ 5 \mathrm{~m} / 10 \mathrm{~m}$ do indivíduo arbóreo analisado.

\section{Influência do indivíduo arbóreos sobre o conforto térmico}

A avaliação da influência exercida pelo indivíduo arbóreo sobre o microclima de seu entorno imediato com vistas à avaliação do conforto térmico foi realizada somente para a espécie sibipiruna, ou seja, por ter sido a que proporcionou melhores resultados em termos de atenuação das variáveis ambientais TBS e CTR e incremento da UR. A avaliação foi conduzida 
aplicando-se critérios de conforto para climas quentes, conforme a Carta Bioclimática de Olgyay (1968), adaptada para habitantes de regiões de climas quentes (Figura 4).

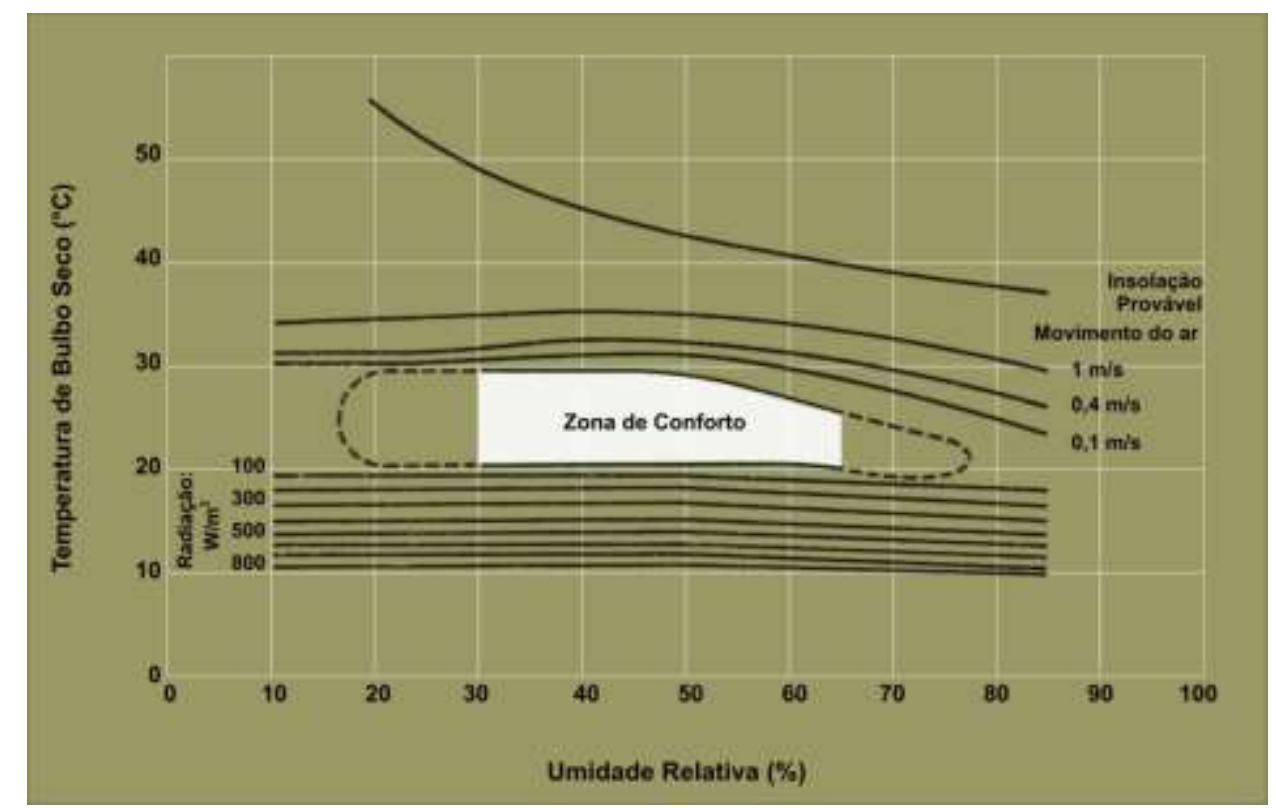

Figura 4. Carta Bioclimática de Olgyay para habitantes de regiões de clima quente, em trabalho leve, vestindo 1 "clo"

Figure 4. Bioclimatic Olgyay Chart for inhabitants from hot regions, under light work, wearing 1 clo

Realizou-se a localização dos pontos na Carta de Olgyay cujas ordenadas referiramse à Temperatura de Bulbo Seco e as abscissas à Umidade Relativa do Ar. Os valores considerados para a análise foram:

a) Os valores das Normais Climatológicas (BRASIL, 1992) (Tabela 1) para os meses relativos às medições em campo, ou seja, setembro, outubro e novembro;

b) A média aritmética das temperaturas diárias máximas do ar, ou seja, correspondentes àquelas verificadas em campo, às 14h, conforme INMET (s.d.) dos três dias considerados para cada indivíduo arbóreo;

c) A média aritmética das Temperaturas de Bulbo Seco, às $10 \mathrm{~h}$ e às $14 \mathrm{~h}$ obtidas em campo, a pleno sol (equipamento posicionado a $15 \mathrm{~m}$ do tronco) e à sombra da árvore, dos três dias de coleta dos dados;

d) A média aritmética das Umidades Relativas do Ar, conforme INMET (s.d.), dos três dias considerados;

e) A média aritmética das Umidades Relativas do $\mathrm{Ar}$, às $10 \mathrm{~h}$ e às $14 \mathrm{~h}$ verificadas em campo, a pleno sol (equipamento posicionado a $15 \mathrm{~m}$ do tronco) e à sombra da árvore, dos três dias de coleta de dados. 
O critério para a definição dos valores utilizados nesta análise pautou-se pelas seguintes considerações:

a) Os valores apresentados pelas Normais Climatológicas representam as tendências do macroclima para a região de Goiânia nos meses que abrangeram o estudo.

b) Os valores do INMET representam àqueles relacionados à mesoescala climática do município de Goiânia-GO, mais especificamente à zona urbana, para os dias nos quais foram realizadas as coletas dos dados.

c) Os valores de Temperaturas de Bulbo Seco (TBS) e Umidades Relativas do Ar (UR), obtidos em campo, às $10 \mathrm{~h}$ e às $14 \mathrm{~h}$, correspondem à microescala climática e representam duas situações extremas. O primeiro horário refere-se à hipótese de que ainda seria possível verificar-se condições de conforto térmico por situar-se no período matutino, quando as trocas térmicas e efeitos proporcionados pela incidência da radiação solar estariam apenas iniciando. O segundo horário refere-se à hipótese de um horário crítico para o conforto térmico para o clima da região e o período do ano considerado, ou seja, ocorre o aumento significativo da temperatura do ar, representada pela TBS e a redução da Umidade Relativa do $\operatorname{Ar}(U R)$;

d) Considerou-se os valores relativos ao equipamento a pleno sol (15m do tronco) e à sombra por representarem as duas situações extremas no que se refere ao conforto térmico. A pleno sol a hipótese é a de desconforto e à sombra a possibilidade da adequação ambiental para dentro dos limites de conforto considerados.

\section{RESULTADOS E DISCUSSÃO}

A Tabela 2 apresenta os valores médios dos dados meteorológicos obtidos para cada indivíduo arbóreo. A sibipiruna, seguida da saboneteira e do barbatimão, demonstraram a presença de raios de influência nas atenuações da temperatura de bulbo seco (TBS), umidade relativa do ar (UR) e Carga Térmica Radiante (CTR) (Tabela 2).

Em geral, houve o incremento da UR do ar na área de abrangência definida pelo estudo, com destaque para sibipiruna e para a saboneteira em todas as posições e horários e do barbatimão a partir das $12 \mathrm{~h}$. No entanto não ficou evidente, como na TBS, a hipótese UR sombra > UR 5 m> UR 10 m (Tabela 2).

Os valores médios das Variações Relativas (VR's) para a TBS, UR e CTR foram considerados para a análise geral dos resultados (Tabela 3 ) e realizada a partir de duas situações: a) o desempenho dos indivíduos arbóreos das espécies estudadas entre si, a partir dos valores percentuais médios encontrados para Variação Relativa (VR\%) da TBS, UR e CTR 
e; b) a confirmação da existência de raios de influência dos indivíduos arbóreos em relação ao seu entorno imediato a partir dos valores médios de Variação Relativa para cada posição (sombra, 5 m e 10 m), comparados dentro de cada horário.

Tabela 2. Valores Médios de Temperatura de Bulbo Seco (TBS, ํㅡ), Umidade Relativa do Ar (UR, \%), e Carga Térmica Radiante (CTR,W $\mathrm{m}^{-2}$ ) obtidos para os indivíduos arbóreos avaliados

Table 2. Average values of Dry Bulb Temperature (TBS, ${ }^{\circ} \mathrm{C}$ ), Relative Air Humidity (UR, \%), and Radiant Heat Load $\left(\mathrm{CTR}, \mathrm{m}^{-2}\right)$ obtained by the individual trees evaluated

\begin{tabular}{|c|c|c|c|c|c|c|c|c|c|c|}
\hline \multirow{4}{*}{ Espécies } & & \multicolumn{3}{|c|}{$10 \mathrm{~h}$} & \multicolumn{3}{|c|}{$12 \mathrm{~h}$} & \multicolumn{3}{|c|}{$14 \mathrm{~h}$} \\
\hline & \multirow{3}{*}{ POSIÇÕES } & \multicolumn{3}{|c|}{ Velocidade do Vento } & \multirow{2}{*}{\multicolumn{3}{|c|}{$\begin{array}{c}\text { Velocidade do Vento }= \\
2,8 \mathrm{~m} \mathrm{~s}^{-1}\end{array}$}} & \multirow{2}{*}{\multicolumn{3}{|c|}{$\begin{array}{c}\text { Velocidade do Vento } \\
=1,7 \mathrm{~m} \mathrm{~s}^{-1}\end{array}$}} \\
\hline & & \multicolumn{3}{|c|}{$=1,0 \mathrm{~m} \mathrm{~s}^{-1}$} & & & & & & \\
\hline & & TBS & UR & CTR & TBS & UR & CTR & TBS & UR & CTR \\
\hline \multirow{4}{*}{ Lanterneiro } & SOMBRA & 29,5 & 44,1 & 503,0 & 32,3 & 37,8 & 528,9 & 34,2 & 33,2 & 577,3 \\
\hline & $5 \mathrm{~m}$ & 33,8 & 38,5 & 511,0 & 38,0 & 30,9 & 578,8 & 38,0 & 29,6 & 625,4 \\
\hline & $10 \mathrm{~m}$ & 35,5 & 27,2 & 571,9 & 36,8 & 25,5 & 610,8 & 37,5 & 24,5 & 671,5 \\
\hline & $15 \mathrm{~m}$ & 36,5 & 33,1 & 544,8 & 39,3 & 27,6 & 592,5 & 39,2 & 27,3 & 632,8 \\
\hline \multirow{4}{*}{ Sibipiruna } & SOMBRA & 30,8 & 37,9 & 494,6 & 34,0 & 29,0 & 516,7 & 35,5 & 26,3 & 533,8 \\
\hline & $5 \mathrm{~m}$ & 30,8 & 37,7 & 491,9 & 34,3 & 30,0 & 521,4 & 36,7 & 24,2 & 605,9 \\
\hline & $10 \mathrm{~m}$ & 31,8 & 34,8 & 507,6 & 36,2 & 27,1 & 612,2 & 37,2 & 23,0 & 617,5 \\
\hline & $15 \mathrm{~m}$ & 35,7 & 26,7 & 561,6 & 37,2 & 20,8 & 612,2 & 38,5 & 18,7 & 617,2 \\
\hline \multirow{4}{*}{ Saboneteira } & SOMBRA & 32,2 & 35,9 & 523,1 & 34,2 & 28,5 & 579,9 & 35,7 & 25,4 & 565,9 \\
\hline & $5 \mathrm{~m}$ & 33,3 & 31,5 & 585,2 & 34,8 & 30,1 & 640,6 & 37,0 & 25,2 & 597,3 \\
\hline & $10 \mathrm{~m}$ & 34,5 & 32,2 & 583,0 & 35,7 & 25,3 & 640,6 & 37,3 & 23,2 & 622,3 \\
\hline & $15 \mathrm{~m}$ & 36,2 & 21,8 & 591,5 & 36,3 & 20,1 & 619,6 & 37,5 & 17,6 & 612,4 \\
\hline \multirow{4}{*}{ Barbatimão } & SOMBRA & 28,5 & 64,8 & 507,7 & 30,3 & 54,9 & 518,6 & 31,7 & 51,7 & 536,0 \\
\hline & $5 \mathrm{~m}$ & 29,7 & 60,2 & 563,1 & 31,8 & 50,2 & 572,5 & 33,0 & 51,1 & 581,4 \\
\hline & $10 \mathrm{~m}$ & 30,0 & 63,8 & 570,4 & 32,0 & 55,3 & 578,3 & 33,2 & 51,3 & 592,1 \\
\hline & $15 \mathrm{~m}$ & 31,2 & 51,4 & 574,6 & 34,3 & 38,8 & 581,7 & 35,0 & 37,4 & 605,8 \\
\hline
\end{tabular}

A Tabela 3 mostra a importância do sombreamento na atenuação da TBS. A espécie lanterneiro proporcionou as maiores atenuações na posição sombra. Em todos os horários os valores situaram-se acima de $12 \%$ de atenuação da TBS, seguida pelo indivíduo de sibipiruna, destacando-se o barbatimão a partir das 12h. As atenuações na posição sombra, em relação ao sol, alcançaram 19\%, no caso do lanterneiro às $10 \mathrm{~h}$, ao passo que a $5 \mathrm{~m}$ as atenuações chegam a $12 \%$ para a sibipiruna às $10 \mathrm{~h}$ e alcançam $10 \%$ na posição $10 \mathrm{~m}$ em relação ao sol, o que demonstra a atuação dos indivíduos arbóreos em seu entorno imediato. 
Tabela 3. Atenuação das variáveis ambientais por cada espécie arbórea avaliada pelas Variações Relativas da Temperatura de bulbo seco (VRTBS), Umidade Relativa do Ar (VRuR) e Carga Térmica Radiante (VRctR) calculadas em relação ao sol e a cada distância analisada

Table 3. Atenuation of the environmental variables by each tree species evaluated by Relative Variations of Dry Bulb Temperature (VRTBS), Relative Air Humidity (VRuR) and Radiant Heat Load (VRctR) calculated in relation to the sun and by each analysed distance

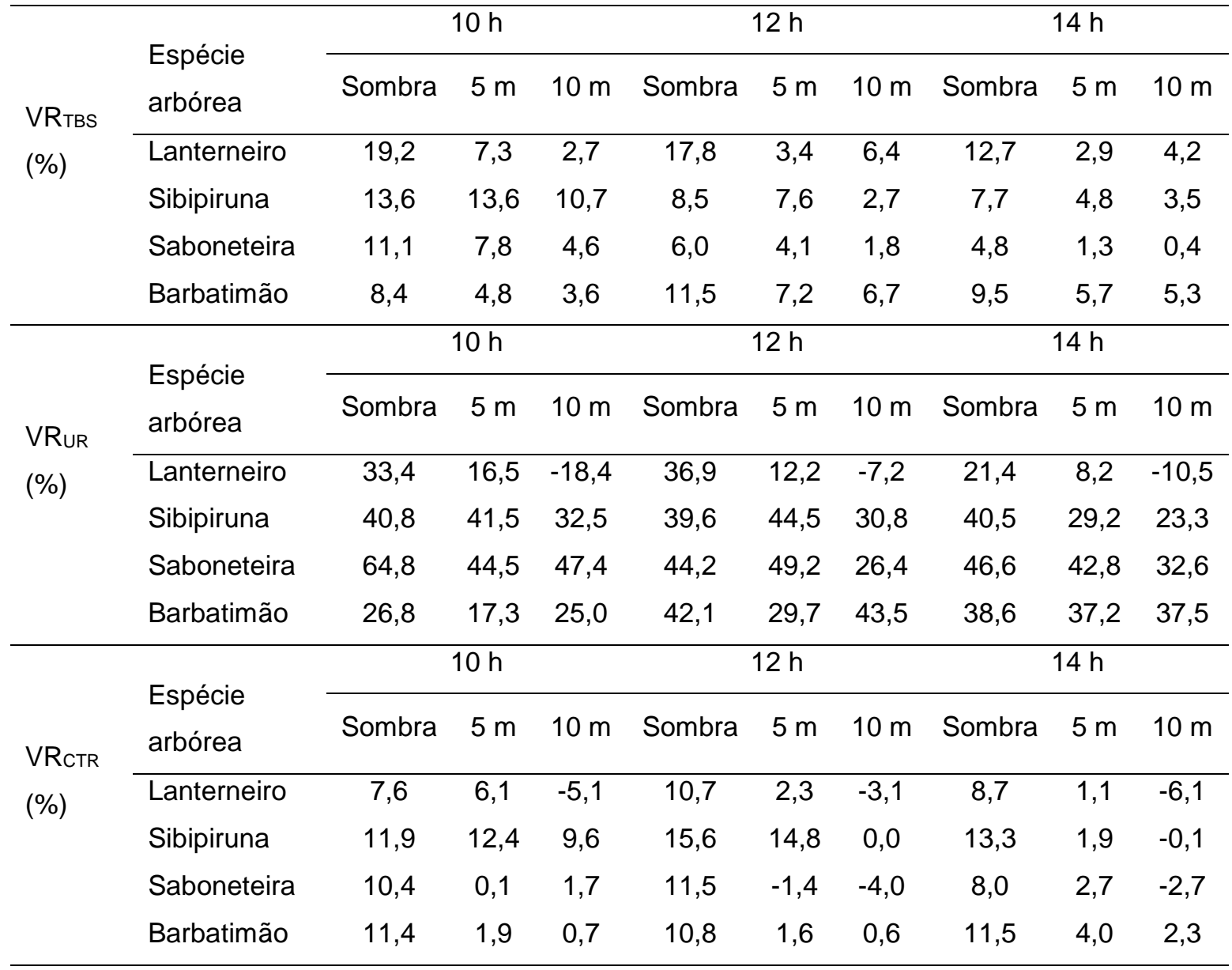

A Variação Relativa no Incremento da UR mostra o melhor desempenho das espécies sibipiruna e saboneteira mesmo no período mais crítico do dia (14h), com incrementos de UR superiores a $40 \%$, nas posições sombra e $5 \mathrm{~m}$. Aos $10 \mathrm{~m}$, os incrementos foram superiores a 25\%.Para a região em estudo, é imprescindível o uso de espécies que não só atenuem a TBS, como também proporcionem um microclima mais ameno em termos de maior concentração de vapor d'água, a partir de seus processos evapotranspiratórios.

Em geral, os resultados confirmam a importância da arborização na interceptação da radiação solar e consequente atenuação da Carga Térmica Radiante. A Tabela 3 mostra que as atenuações da CTR na posição sombra, em todos os horários, apresentaram valores superiores a $8 \%$ e, no caso da Sibipiruna, atingindo 15\% de atenuação da CTR.

Abreu-Harbich; Labaki; Matzarakis (2015), avaliando o efeito de diferentes arquiteturas de copas sobre o conforto térmico humano em condições tropicais, reportam, também, uma 
maior atenuação da sibipiruna na posição sombra em relação à posição sol, com atenuaçõesde até $84 \%$ entre os períodos das $10 \mathrm{~h}$ e $14 \mathrm{~h}$.

Os dados de Temperatura de Bulbo Seco (TBS) demonstram, claramente, a existência do raio de influência sobre as variáveis ambientais relacionadas às modificações dos microclimas (Tabela 2). A Figura 5mostra que o comportamento da TBS, para as quatro posições dos equipamentos, demonstra a hipótese inicial da existência do raio de influência sobre o microclima. A proximidade das linhas referentes ao equipamento à sombra e a $5 \mathrm{~m}$ do tronco até as $12 \mathrm{~h}$ (Figura 5) ocorreu porque até este horário, devido à dimensão da copa, o equipamento a $5 \mathrm{~m}$ encontrava-se à sombra (10h) ou muito próximo à mesma (12h), o que demonstra a importância do sombreamento na atenuação desta variável ambiental. Percebese, ainda, que a diferença entre os valores à sombra e a $15 \mathrm{~m}$ (condição a pleno sol) situou-se na ordem de $5^{\circ} \mathrm{C}$ para a sibipiruna no início das medições, diminuindo ao longo do período de monitoramento. No entanto essa diferença não foi inferior a $3^{\circ} \mathrm{C}$, ou seja, $38,5^{\circ} \mathrm{C}$ e $35,5^{\circ} \mathrm{C}$, a pleno sol e à sombra, respectivamente.

O comportamento das relações sol / sombra, sol / $5 \mathrm{~m}$ e sol / 10m entre si, no caso do cálculo das Variações Relativas (Figura 5), também corrobora a hipótese do raio de influência dos indivíduos arbóreos das espécies estudadas e do efeito positivo do sombreamento na atenuação da TBS. Ao longo do período analisado (das 10h às 14h) as atenuações apresentaram uma sequência em que: atenuação sol / sombra $\geq$ atenuação sol / 5 m>atenuação sol /10 m. Esta relação demonstra: i) a capacidade do indivíduo arbóreo atuar sobre a TBS em seu entorno imediato, considerando-se, neste caso, um raio de influência de $15 \mathrm{~m}$; ii) o sombreamento proporciona a atenuação da radiação solar quando é analisada a relação sol / $5 \mathrm{~m}$ a partir das $12 \mathrm{~h}$, momento em que o equipamento 2 não se encontra mais à sombra e, portanto, a atenuação proporcionada à essa distância diminui ao longo do período, mas não sendo inferior à relação sol / 10 m em nenhum momento.

Dentre as espécies estudadas, a sibipiruna foi a que demonstrou claramente a ocorrência de raios de influência sobre as variáveis ambientais, confirmando a hipótese da influência sobre o microclima do seu entorno imediato. Ressalta-se que a hipótese foi confirmada, também, para a Carga Térmica Radiante e a Umidade Relativa do Ar.

Ficou comprovada, ainda, a importância do sombreamento na atenuação da incidência da radiação solar e, consequentemente, na atenuação da CTR nos resultados relativos aos equipamentos posicionados à sombra. Em todos os casos houve a atenuação da CTR à sombra, com destaque ao indivíduo de sibipiruna. Estas constatações foram corroboradas pela comparação das espécies entre si, sendo que as espécies sibipiruna, saboneteira e barbatimão alcançaram bons desempenhos de atenuação da CTR, sobressaindo-se a primeira, cujo diâmetro e densidade das copas são maiores. 


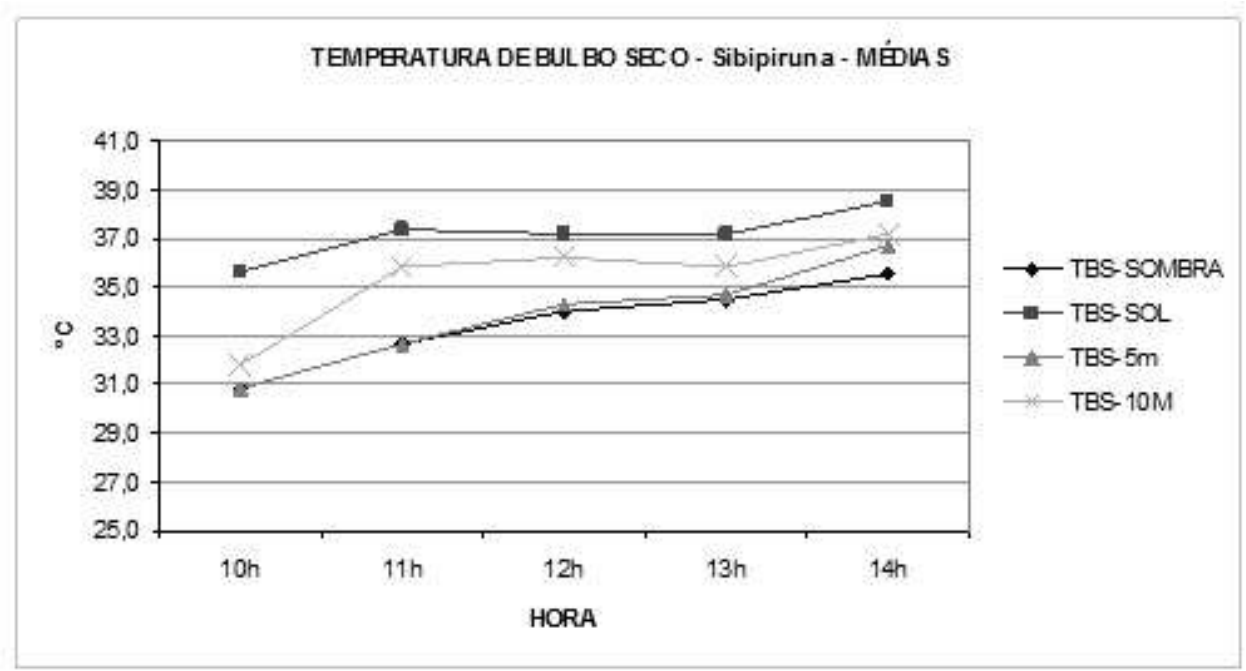

Figura 5. Médias das Temperaturas de Bulbo Seco considerando os raios de influência determinados a partir do tronco à sombra, $5 \mathrm{~m}, 10 \mathrm{~m}$ e $15 \mathrm{~m}$ (sol) para o indivíduo arbóreo de Cesalpina pluviosa (sibipiruna)

Figure 5. Average of dry bulb temperatures considering the ray of influence from the trunk under the shadow, $5 \mathrm{~m}, 10 \mathrm{~m}$ and $15 \mathrm{~m}$ (sun) for the Cesalpina pluviosa individual

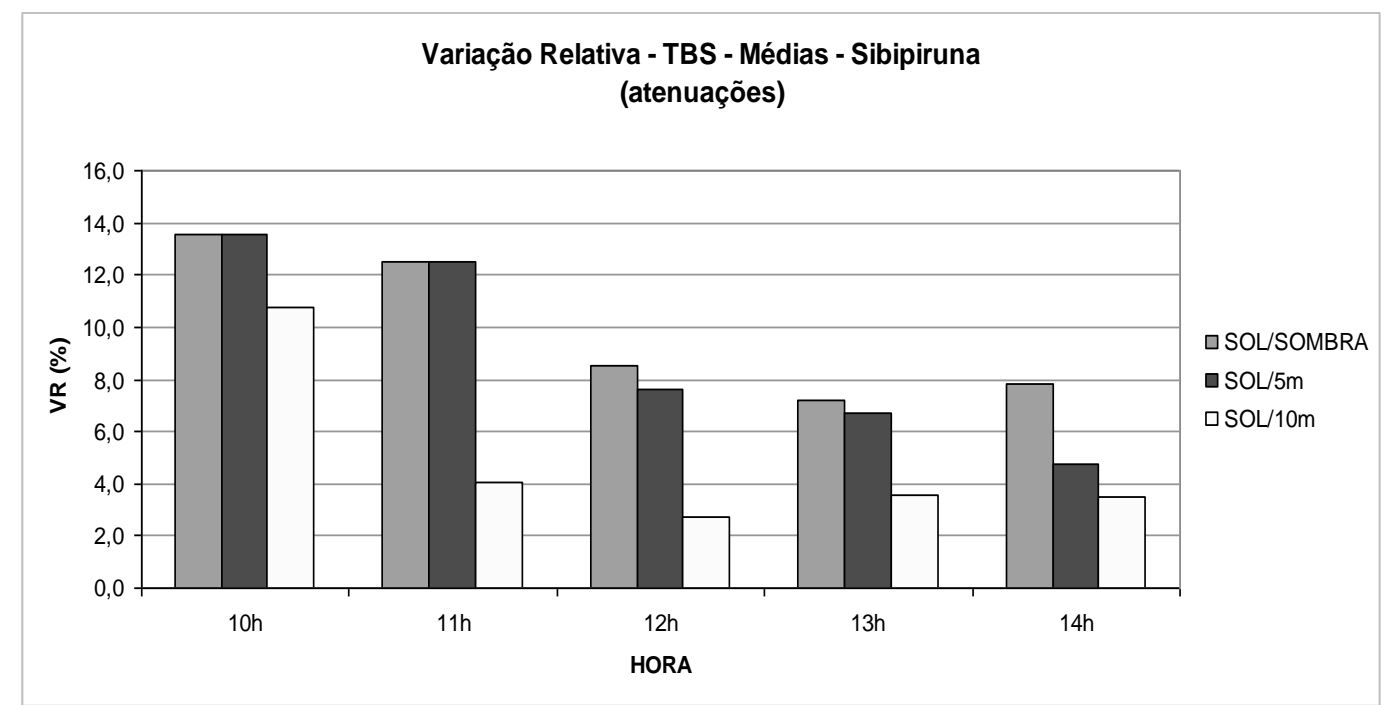

Figura 6. Variações Relativas (VR) da atenuação da Temperatura de Bulbo Seco (TBS) a partir da comparação das Temperaturas de Bulbo Seco à sombra, a $5 \mathrm{~m}$ e a $10 \mathrm{~m}$ com a TBS ao sol (15 $\mathrm{m}$ do tronco) do indivíduo arbóreo de Cesalpina pluviosa (sibipiruna)

Figure 6. Relative Variation (VR) of the dry bulb temperature attenuation from the comparison of the dry bulb temperatures in the shadow from $5 \mathrm{~m}, 10 \mathrm{~m}$ and $15 \mathrm{~m}$ (sun) for the Cesalpina pluviosa individual

Assim sendo, os efeitos benéficos das árvores nos ambientes urbanos devem ser melhor explorados, utilizando-se da arborização como importante estratégia em projetos ambientais que visem, dentre outros, a redução das temperaturas urbanas e seus efeitos maléficos. Da mesma forma, Gill et al. (2007), ressaltam que quaisquer programas de arborização urbana deveriam ser adequadamente projetados e monitorados para que haja uma 
avaliação continuada de seu benefício para a saúde humana em termos de redução da temperatura e controle de poluição.

\section{Análise de conforto térmico}

A seguir, são apresentados os resultados para a sibipiruna, espécie que alcançou os melhores resultados entre as demais estudadas, em termos de atenuação da TBS, UR e CTR e aumento da UR.

A partir dos valores das variáveis ambientais (Tabela 4), a análise de conforto térmico foi realizada mediante a localização desses valores na Carta Bioclimática de Olgyay (Figura 7) e a comparação de suas posições em relação à zona gráfica correspondente à situação de conforto térmico.

A posição do ponto NC, correspondente às Normais Climatológicas para o município de Goiânia, indica que os valores de TBS e UR encontram-se fora da zona de conforto, sendo possível atingi-la por meio da movimentação do ar, na ordem de $0,4 \mathrm{~m} \mathrm{~s}^{-1}$, bem abaixo do valor de $3 \mathrm{~m} \mathrm{~s}^{-1}$ indicado pelas Normais Climatológicas (Tabela 1), como média da velocidade do vento para o mês de outubro.

Tabela 4. Temperatura de Bulbo Seco (TBS) e Umidade Relativa do Ar (UR) do indivíduo arbóreo de Caesalpinia pluviosa (sibipiruna) para comparação com os critérios de conforto térmico de Olgyay.

Table 4. Values of Dry Bulb Temperature (TBS) and Relative Air Humidity (UR) of the arboreal individual of Caesalpinia pluviosa for comparison with the criteria of Olgyay thermal comfort.

\begin{tabular}{|c|c|c|c|c|c|c|}
\hline \multirow{2}{*}{ Variáveis ambientais } & \multirow{2}{*}{ Normais Climatológicas } & \multirow{2}{*}{ INMET $^{1}$} & \multicolumn{2}{|c|}{ Sol } & \multicolumn{2}{|c|}{ Sombra } \\
\hline & & & $10 \mathrm{~h}$ & $14 \mathrm{~h}$ & $10 \mathrm{~h}$ & $14 \mathrm{~h}$ \\
\hline $\operatorname{TBS}\left({ }^{\circ} \mathrm{C}\right)$ & 31,0 & 36,5 & 37,7 & 38,5 & 30,8 & 35,5 \\
\hline UR (\%) & 65,0 & 32,0 & 26,7 & 18,7 & 37,9 & 26,3 \\
\hline
\end{tabular}




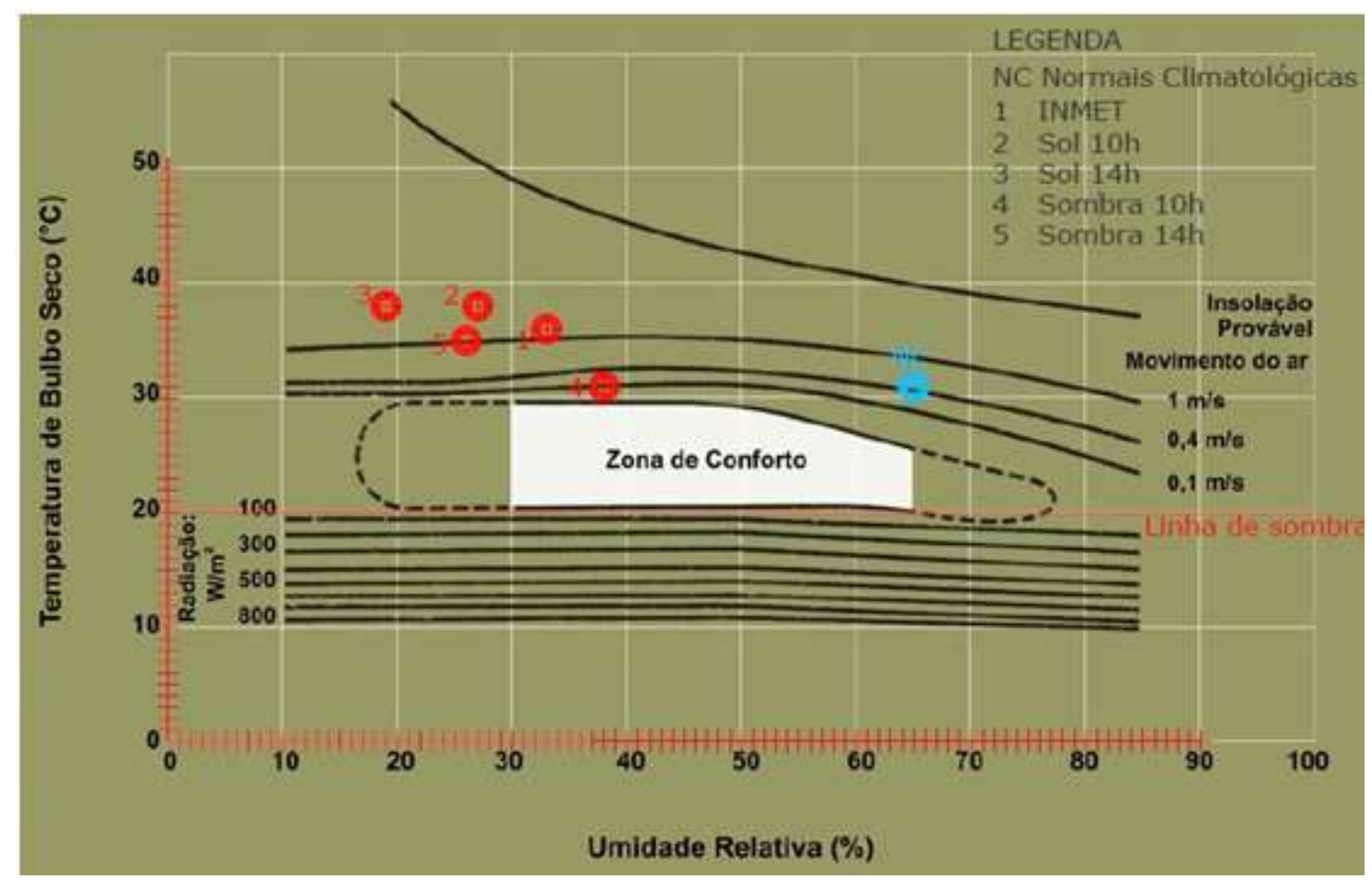

Figura 7. Carta Bioclimática de Olgyay adaptada para habitantes de regiões de clima quente, em trabalho leve, vestindo 1 "clo" $\left(0,155 \mathrm{~m}^{2}{ }^{\circ} \mathrm{C}^{-1} \cdot \mathrm{W}^{-1}\right)$, com a plotagem dos valores de temperatura de bulbo seco e umidade relativa do ar para a Cesalpina pluviosa (sibipiruna)

Figure 7. Olgyay Bioclimatic Chart adapted for inhabitants from hot climate regions, under light labor, wearing 1 "clo" $\left(0.155 \mathrm{~m}^{2}{ }^{\circ} \mathrm{C}-1\right.$. W-1), with the plotting of dry bulb temperature and relative air humidity for Cesalpina pluviosa (sibipiruna)

Uma observação relevante é o distanciamento do valor de NC dos demais valores obtidos em campo para as espécies arbóreas (posições 2, 3, 4 e 5) e daquele divulgado pelo INMET (posição 1) para os dias em questão. Esta situação fornece indícios sobre a formação dos microclimas urbanos, uma vez que aos valores indicados pelas Normais Climatológicas representam o macro clima para a região do município de Goiânia.

Observa-se que todos os pontos se encontram fora dos limites estabelecidos para a Zona de Conforto para climas quentes, no entanto, destacam-se os pontos 1, 4 e 5, para os quais o aumento da velocidade do vento, ou movimentação do ar, possibilita atingir a zona de conforto.

O ponto 1 representa os dados do INMET (2015) e demonstra, para as médias das máximas diárias e UR do período, que o sombreamento e movimentação do ar podem proporcionar limites aceitáveis para o conforto térmico, neste caso. Comparando o ponto 1 com os pontos 2 e 3 (pleno sol às 10h e 14h), verifica-se que estes, confirmam a geração de microclima no local onde se encontra a árvore, ou seja, um microclima tipicamente urbano de desconforto térmico.

O ponto 4 , equipamento à sombra às $10 \mathrm{~h}$, mostra que, além do sombreamento, uma pequena movimentação do ar promove situação de conforto. Portanto pode-se afirmar que o 
sombreamento proporcionado pela sibipiruna promove conforto térmico, pois a Velocidade do Vento (Vv) média observada em campo para os três dias estudados, para este horário, foi de $0,7 \mathrm{~m} \mathrm{~s}^{-1}$ (Tabela 2) ao passo que a Carta indica uma $\mathrm{Vv}$ de $0,1 \mathrm{~m} \mathrm{~s}^{-1}$ para que haja conforto.

O mesmo raciocínio aplica-se ao ponto 5 (sombra às 14h). Embora se situe acima da Zona de Conforto e do ponto 4, uma movimentação do ar na ordem de $1 \mathrm{~m} \mathrm{~s}^{-1}$ (Tabela 2), promoveria uma condição de conforto. Como o valor médio de $\mathrm{Vv}$ registrado nos dias estudados foi de $1,7 \mathrm{~m} \mathrm{~s}^{-1}$, pode-se afirmar, novamente, que o sombreamento proporcionado pela sibipiruna promove conforto térmico, a partir dos pressupostos da Carta Bioclimática de Olgyay para climas quentes. Assim sendo, confirma-se a hipótese de que o sombreamento proporcionado pela sibipiruna promove adequação ambiental em termos de conforto térmico.

\section{CONCLUSÕES}

Foi estudada a influência de diferentes espécies arbóreas na melhoria do microclima do seu entorno imediato. Conclui-se que houve atenuações expressivas das temperaturas ambientais (TBS) e da Carga Térmica Radiante, demonstrando que há um escalonamento gradativo e inversamente proporcional da contribuição dos indivíduos arbóreos estudados com relação à distância de seu tronco.

As espécies que se destacaram foram a sibipiruna e o barbatimão que apresentaram médias gerais de atenuações da temperatura de bulbo seco entre $5 \%$ e $10 \%$. A saboneteira e a sibipiruna proporcionaram os maiores incrementos na umidade relativa, superiores a $30 \%$,e a sibipiruna, à sombra, proporcionou atenuações na Carga Térmica Radiante na ordem de 15\%.

A partir dos pressupostos da Carta Bioclimática de Olgyay para climas quentes, confirma-se a hipótese de que o sombreamento proporcionado pela sibipiruna promove adequação ambiental em termos de conforto térmico.

Portanto demonstrou-se a influência das espécies arbóreas estudadas na melhoria do microclima do seu entorno imediato. O estudo apresentou resultados positivos e propõe uma metodologia simples, a partir da adaptação de outras, para a quantificação dos efeitos da atenuação térmica por indivíduos arbóreos nos ambientes urbanos e consequente avaliação do conforto térmico humano. 


\section{REFERÊNCIAS}

ABREU-HARBICH, L. V., LABAKI, L. C. Conforto térmico propiciado por algumas espécies arbóreas: avaliação do raio de influência através de diferentes índices de conforto. Ambiente Construído, Porto Alegre, v.10, n 4, p.103-117, 2010.

ABREU-HARBICH, L. V., LABAKI, L. C., MATZARAKIS, A. Effect of tree planting design and tree species on human thermal comfort in the tropics. Landscape and Urban Planning, v.138, p.99-109, 2015.

AMMA. AGÊNCIA MUNICIPAL DE MEIO AMBIENTE DE GOIÂNIA. Plano Diretor de Arborização Urbana de Goiânia. Disponível em: <http://www.goiania.go.gov.br>. Acesso em 15 mar 2015.

BARTOLOMEI, C. L. Influência da vegetação no conforto térmico urbano e no ambiente construído. 2003. 189f. Tese (Doutorado em Engenharia Civil) - Faculdade de Engenharia Civil, Universidade Estadual de Campinas, Campinas, 2003.

BRASIL. Departamento de Meteorologia. Ministério da Agricultura e Reforma Agrária. Normais Climatológicas. Brasília, 1992.

BUENO, C. L. Estudo da atenuação da radiação solar incidente por diferentes espécies arbóreas. 1998. 176f. Dissertação (Mestrado em Engenharia Civil) - Faculdade de Engenharia Civil, Universidade Estadual de Campinas, Campinas, 1998.

DACANAL, C.; LABAKI, L. C.; SILVA, T. M. L. Vamos passear na floresta! O conforto térmico em fragmentos florestais urbanos. Ambiente Construído, Porto Alegre, v. 10, n. 2, p. 115-132, 2010.

DONOVAN, G. H.; BUTRY, D. T. The value of shade: Estimating the effect of urban trees on summertime electricity use. Energy and Buildings, v.41, p.662-668, 2009.

ESMAY, M. L. Principles of animal environment. Environmental Engineering in Agriculture and Food Series. The AVI Publishing Company, Inc. 1979. 325p.

GILL, S., HANDLEY, J., ENNOS, R., PAULEIT, S. Adapting cities for climate change: the role of the green infrastructure. Built Environment,. v. 30, p. 97-115, 2007.

INMET. INSTITUTO NACIONAL DE METEOROLOGIA. Banco de Dados Meteorológicos para Ensino e Pesquisa. Disponível em: <http://www.inmet.gov.br/portal/index.php?r=bdmep /bdmep>. Acessoem: 15 mar 2015.

INTERNACIONAL ORGANIZATION FOR STARDARDIZATION (ISO). Ergonomics of the thermal environment - Instruments formeasuring physical quantities, ISO 7726. Genebra, 1998.

KOTTEK, M.; GRIESER, J.; BECK, C.; RUDOLF, B.; RUBEL, F. World Map of the KöppenGeiger climate classification updated. Meteorologische Zeitschrift, Berlin, v.15, n.3, p. 259263, 2006.

LABAND, D. N. An experimental analysis of the impact of tree shade on electricity consumption. Arboriculture and Urban Forestry, v.35, n.4, p.197-202, 2009. 
LIN, T. P.; MATZARAKIS; A.; HWANG, R. L. Shading effect on long-term outdoor thermal comfort. Building and Environment, v. 45, p. 213-221, 2010.

MARTINI, A.; BIONDI, D.; BATISTA, C. B.; ZAMPRONI, K.; VIEZZER, J.; GRISE, M. M.; LIMA NETO, E. M. Percepção da população sobre o conforto térmico proporcionado pela arborização de ruas de Curitiba-PR. Floresta, Curitiba, v.44, n.3, p.515-524, 2014.

MEIRA, G. R. N., TEIXEIRA, G. G. M., VENTURINI, P. R. F., GOTTSTEIN, P., CAXAMBU, M. G. Avaliação quali-quantitativa de espécies arbóreas no perímetro urbano da cidade de Corumbataí do Sul - PR. Revista da Sociedade Brasileira de Arborização Urbana, Piracicaba. v.10, n.4, p.36-49, 2015.

MINELA, F. C.; HONJO, S. KRÜGER, E. L. Estratégias de melhoria do ambiente térmico diurno em situação de verão de uma fração urbana da cidade de São Paulo. Ambiente Construído, Porto Alegre, v.12, n.4, p.139-158, 2012

NASCIMENTO, D. T. F.; OLIVEIRA, I. J. Análise da evolução do fenômeno de ilhas de calor no município de Goiânia-GO (1986-2010). Boletim Goiano de Geografia, Goiânia, v. 31, n.2, p.113-127, 2011.

NÓBREGA, R. S., VITAL, L. A. B.Influência da Urbanização sobre o Microclima de Recife e Formação de Ilha de Calor, Revista Brasileira de Geografia Física, Recife, v.3, p.151-156, 2010.

OLGYAY, V. Clima y Arquitectura en Colômbia. Universidad del Valle, Cali, Colômbia, 1968.

PANDIT, R.; LABAND, D. N. Energy savings from tree shade. Ecological Economics, v.69 p.1324-1329, 2010.

SANTOS JÚNIOR, A., LACERDA, E. S., GOMES, W. O. A arborização pública e a eficiência do sombreamento da superfície urbana em bairros residenciais de Porto Velho, RO. Revista da Sociedade Brasileira de Arborização Urbana, Piracicaba, v.8, n.3, p.108-117, 2013.

SATTLER, M. A. Medições de campo de transmissão da radiação solar através de árvores. In: ENCAC - ENCONTRO NACIONAL DE CONFORTO NO AMBIENTE CONSTRUÍDO, 1, 1991, Gramado. Anais... Porto Alegre: Associação Nacional de Tecnologia do Ambiente Construído, 1991. p.93-96.

SPANGENBERG, J., SHINZATO, P., JOHANSSON, E. DUARTE, D. Simulation of the influence of vegetation on microclimate and thermal comfort in the city of São Paulo. Revista da Sociedade Brasileira de Arborização Urbana, Piracicaba, v.3, n.2, p.1-19, 2008. 